\title{
PLANT-MICROBE-INSECT INTERACTIONS Evolutionary adaptation in three-way interactions between plants, microbes and arthropods
}

\author{
Arjen Biere ${ }^{*, 1}$ and Ayco J. M. Tack ${ }^{2}$ \\ ${ }^{1}$ Department of Terrestrial Ecology, Netherlands Institute of Ecology, NIOO-KNAW, Droevendaalsesteeg 10, 6708 PB, \\ Wageningen, The Netherlands; and ${ }^{2}$ Metapopulation Research Group, Department of Biosciences, University of \\ Helsinki, P. O. Box 65 (Viikinkaari 1), Fl-00014, Helsinki, Finland
}

\section{Summary}

1. Evolutionary adaptations in interactions between plants, microbes and arthropods are generally studied in interactions that involve only two of these groups, that is, plants and microbes, plants and arthropods or arthropods and microbes.

2. We review the accumulating evidence from a wide variety of systems, including plant- and arthropod-associated microbes, and symbionts as well as antagonists, that selection and adaptation in seemingly two-way interactions between plants and microbes, plants and arthropods and arthropods and microbes are often driven by the biotic context of a third partner.

3. We extend the concept of local adaptation from two-way interactions to scenarios for threeway interactions. We show that consumers can locally adapt to specific host phenotypes that are induced by a third species with which they do not directly interact. This emphasizes that indirect interactions have not only ecological but also important evolutionary consequences, and stresses the need to conduct studies of local adaptation in the proper ecological context of the species involved.

4. Overall, our review underlines the importance of three-way interactions in the evolution of plant-microbe, plant-arthropod and arthropod-microbe interactions, and we outline some promising directions for future research.

Key-words: co-evolution, genotype-by-environment interactions, local adaptation, plant-insect interactions, plant-microbe-arthropod interactions, plant-pathogen interactions, symbionts, tripartite interactions

\section{Evolutionary three-way interactions between plants, microbes and arthropods}

Species interactions can drive evolutionary or co-evolutionary change in species, resulting in adaptive differentiation within and between populations that can eventually lead to ecological speciation (Schluter 2009). In recent years, it has become clear that not only antagonistic interactions, but also mutualistic interactions can drive such evolutionary or co-evolutionary diversification (e.g. Janson et al. 2008; Hoeksema 2010). Species interactions can therefore promote and maintain much of the biological diversity that we see in natural systems. Interspecific interactions occur within taxa, but also between taxa as diverse as plants, microbes and animals. Here, we focus on interactions between plants, microbes and arthropods. While our understanding of direct two-way interactions between plants and

*Correspondence author. E-mail: a.biere@nioo.knaw.nl microbes, plants and arthropods and arthropods and microbes has a solid fundamental in the disciplines of ecology and evolution (Begon, Harper \& Townsend 2005), studies exploring how indirect interactions among these three taxa (Fig. 1) may drive ecological and evolutionary patterns and processes have only recently been initiated.

Such three-way interactions between plants, arthropods and microbes can have important consequences for the performance of species in their local community (Barbosa, Krischik \& Jones 1991); for example, the presence and identity of plant-associated microbes can affect the performance of arthropods on their shared host plants and vice versa (e.g. Jones 1984; Hatcher 1995; Felton \& Korth 2000; Stout, Thaler \& Thomma 2006; Pieterse \& Dicke 2007; Hartley \& Gange 2009; Tack \& Dicke 2013), microbial endosymbionts can affect the performance of their arthropod hosts depending on food plant (e.g. Ferrari \& Vavre 2011; White 2011), and plants can affect the susceptibility of arthropods to their microbial pathogens 


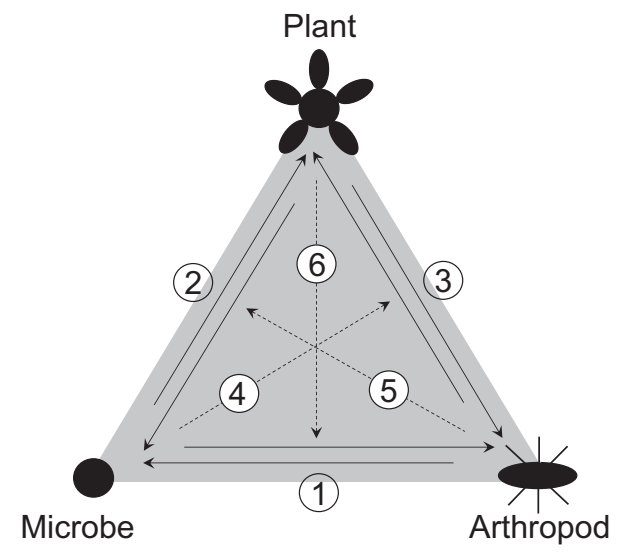

Fig. 1. Direct and indirect interactions between plants, microbes and arthropods. Solid arrows (1-3) represent direct interactions; organisms at the tail of arrows ('agents') cause changes in the phenotype or performance of organisms at the head of arrows ('targets') and can exert direct selection on target organisms. Dashed arrows (4-6) indicate that organisms indirectly modulate the interactions between two other organisms. For instance, selection exerted by microbes on arthropods can be direct (e.g. endosymbionts or entomopathogens affecting arthropod performance independent of food plant, arrow 1), but also indirect, for instance when plant pathogens affect the (the distribution of) plant phenotypes, which subsequently affects the performance and/or evolution of a herbivorous insect (arrows 2 and 3, respectively), or when microbes affect arthropod traits that subsequently affect the arthropod's interaction with its food plants (both captured by arrow 4).

(e.g. Cory \& Hoover 2006). There is now emerging evidence that such three-way interactions between plants, arthropods and microbes can play a major role in shaping ecological communities (e.g. Frago, Dicke \& Godfray 2012; Tack \& Dicke 2013). However, an evolutionary framework for understanding under which conditions 'third parties' can drive evolutionary change and even promote or impede adaptive evolutionary diversification in interactions between two other species has only recently been initiated (Janson et al. 2008). Two types of studies can inform us about the role of three-way interactions between plants, microbes and arthropods in evolutionary and co-evolutionary diversification and adaptation of the species involved: (i) studies examining contemporary patterns of heritable variation, selection and adaptation in interacting species and (ii) studies inferring longer-term evolutionary patterns in traits involved in species interactions using, for example, phylogenetic and molecular analyses. Below, we first briefly outline when and how these types of studies can be interpreted in the context of threeway interactions and show how the concept of local adaptation can be simply extended from a framework of two-way interactions to scenarios for three-way interactions.

\section{HERITABLE VARIATION, SELECTION AND ADAPTATION IN THREE-WAY INTERACTIONS}

For one species to drive evolutionary change in another requires that it exerts significant and consistent selection on heritable trait variation in that species. Co-evolutionary change requires in addition that there is reciprocal selection, such that the fitness of the genotype of one species is dependent on the genotype of the species with which it interacts (genotype-by-genotype or $\mathrm{G} \times \mathrm{G}$ interaction). It has long been realized that the abiotic component of the environment can affect the strength and direction of selection and the local evolutionary outcome of two-way interactions between hosts and their interacting antagonists (Wolinska \& King 2009) or beneficial organisms (Hoeksema 2010). This can be observed in the form of genotypeby-environment $(\mathrm{G} \times \mathrm{E})$ interactions for fitness in at least one of the species, or genotype-by-genotype-by-environment $(\mathrm{G} \times \mathrm{G} \times \mathrm{E})$ interactions for fitness, indicating opportunities for locally variable evolution and co-evolution, respectively (Table 1). There is emerging evidence for $\mathrm{G} \times \mathrm{G} \times \mathrm{E}$ interactions (Wolinska \& King 2009), indicating local variability in the outcome of species interactions, one of the pillars underlying the geographical mosaic of co-evolution hypothesis (Thompson 1999) and thought to be an important mechanism for maintaining polymorphisms in host-parasite interactions (Laine \& Tellier 2008). For three-way interactions between plants, arthropods and microbes to play an important role in evolutionary diversification of the species involved, it is essential that not only the abiotic but also the biotic component of the environment can modulate the evolutionary or co-evolutionary outcome between two species. In other words, we should observe that the community context alters the pattern of (reciprocal) selection that two species exert on each other's ecologically important traits (Strauss, Sahli \& Conner 2005). As an example, interactions between barley genotypes and aphid clones are affected by the presence or absence of rhizobacteria (Tétard-Jones et al. 2007), as evidenced by a significant G[aphid] $\times$ G[barley] $\times$ E[rhizobacteria] interaction for aphid fitness. In principle, the interaction between barley genotypes and aphid genotypes may be further dependent on the genotype of the rhizobacterial species associated with the plant, giving rise to more complex $\mathrm{G} \times \mathrm{G} \times \mathrm{G}$ or $\mathrm{G} \times \mathrm{G} \times \mathrm{G} \times \mathrm{E}$ interactions (Table 1). Although it has been argued that the presence of additional species, resulting in more diffuse co-evolution, might decrease the strength and consistency of selection between any pair of species, it is important to realize that there is no a priori reason that the presence of additional species would reduce the opportunity for any species to be an important driver of trait diversification in another species (Thrall et al. 2007; Hoeksema 2010). Rather, the selection patterns may be more complex.

\section{THE CONCEPT OR LOCAL ADAPTATION IN THREE-WAY INTERACTIONS}

When, as outlined above, a third species has the potential to affect the evolution or co-evolution of the two interacting species by altering the pattern of fitness interactions between their genotypes, it becomes interesting to examine 
Table 1. Types of interactions that can potentially drive evolutionary or co-evolutionary diversification in plant-microbe-arthropod interactions. An example is given for a plant-associated microbe (M) affecting the interaction between a plant (P) and an arthropod (A), but similar tables can be constructed for arthropod-associated microbes, for arthropods affecting plant-microbe interactions or for plants affecting arthropod-microbe interactions. Plant and arthropod genotypes either experience variation in the presence/absence of a plantassociated microbe $\left(\mathrm{E}_{\mathrm{M}}\right)$ or experience different genotypes of the plant-associated microbe $\left(\mathrm{G}_{\mathrm{M}}\right)$. The plant and arthropod genotypes then either do not respond (or do not differ in their response) to the plant-associated microbe (Fixed) or show genetic variation in their response within or between populations (Different). Observed interaction types in bold are interactions between arthropod genotypes $\left(G_{A}\right)$, plant genotypes $\left(G_{P}\right)$ and microbial presence/absence $\left(E_{M}\right)$ or genotype $\left(G_{M}\right)$ (detected for plant or arthropod traits involved in the interaction) that facilitate microbial impact on plant-arthropod co-evolution. Types of interactions that facilitate microbial impact on the evolution of plant or arthropod traits, but not necessarily their co-evolution are indicated in regular font

\begin{tabular}{|c|c|c|c|c|}
\hline $\begin{array}{l}\text { Type of variation in } \\
\text { plant-associated microbe (M) }\end{array}$ & $\begin{array}{l}\text { Response of plant }(\mathrm{P}) \\
\text { genotypes }\end{array}$ & $\begin{array}{l}\text { Response of arthropod (A) } \\
\text { genotypes }\end{array}$ & $\begin{array}{l}\text { Type of interaction for } \\
\text { plant trait }\end{array}$ & $\begin{array}{l}\text { Type of interaction for } \\
\text { arthropod trait }\end{array}$ \\
\hline \multirow[t]{4}{*}{ Presence/absence } & \multirow[t]{2}{*}{ Fixed } & Fixed & - & - \\
\hline & & Different & - & $\mathrm{G}_{\mathrm{A}} \times \mathrm{E}_{\mathrm{M}}$ \\
\hline & \multirow[t]{2}{*}{ Different } & Fixed & $\mathrm{G}_{\mathrm{PX}} \mathrm{E}_{\mathrm{M}}$ & - \\
\hline & & Different & $\mathbf{G}_{\mathbf{P}} \times \mathbf{G}_{\mathbf{A}} \times \mathbf{E}_{\mathbf{M}}$ & $\mathbf{G}_{\mathbf{A}} \times \mathbf{G}_{\mathbf{P}} \times \mathbf{E}_{\mathbf{M}}$ \\
\hline \multirow[t]{4}{*}{ Genotypic variation } & \multirow[t]{2}{*}{ Fixed } & Fixed & - & - \\
\hline & & Different & - & $G_{A} \times G_{M}$ \\
\hline & \multirow[t]{2}{*}{ Different } & Fixed & $\mathrm{G}_{\mathrm{P}} \times \mathrm{G}_{\mathrm{M}}$ & - \\
\hline & & Different & $\mathbf{G}_{\mathbf{P}} \times \mathbf{G}_{\mathbf{A}} \times \mathbf{G}_{\mathbf{M}}$ & $\mathbf{G}_{\mathbf{A}} \times \mathbf{G}_{\mathbf{P}} \times \mathbf{G}_{\mathbf{M}}$ \\
\hline
\end{tabular}

the exact pattern of such $\mathrm{G} \times \mathrm{G} \times \mathrm{E}$ or $\mathrm{G} \times \mathrm{G} \times \mathrm{G}$ interactions. This will reveal whether there is any local adaptation within the three-way interaction and, if so, who is locally adapted to whom. In two-way interactions, for instance between hosts and parasites, the diagnostic pattern for parasite local adaptation is that parasite genotypes originating from the local population of their hosts have higher fitness on these hosts than parasite genotypes that originate from other host populations (the so-called local versus foreign comparison, sensu Kawecki \& Ebert 2004). Parasite local adaptation has been predicted for microbial parasites of animal or plant hosts based on the generally higher evolutionary potential of microbes compared with their plant or animal hosts owing to their usually shorter generation times, higher mutation rates and larger population sizes. However, meta-analyses of experimental studies have failed to show that parasite local adaptation is the general pattern (Greischar \& Koskella 2007; Hoeksema \& Forde 2008), underlining that many additional factors such as their relative migration rates affect opportunities for local adaptation (e.g. Gandon 2002). In three-way interactions, the range of outcomes is clearly more complex, as illustrated by just five of the more extreme cases of arthropod responses to local and non-local genotypes of their food plant and a food plant-associated microbe (Fig. 2). In the simplest scenario, arthropods may adapt to their local food plants, independent of a plant-associated microbe (Fig. 2a). Alternatively, arthropods may adapt to the specific combination of local host plant and microbe (Fig. 2b), the microbe may alter the extent or direction of local adaptation of the arthropod to the plant in various other ways (Fig. 2c), or the arthropod may be adapted to the plant phenotypes induced by the local plant-associated microbe, independent of the genotype and origin of the mediating plant, that is, even when it is not adapted to the host plant itself that is harbouring the microbe (Fig. 2d). Finally, the arthropod may not be locally adapted to plant or microbe at all (Fig. 2e). It should be noted that the illustrated scenarios all focus on local adaptation of the arthropod. If we want to assess whether in these scenarios the other players, plants and microbes, are locally (mal-) adapted to each of the species with which they interact, we would need additional information on the fitness parameters of the plants and microbes themselves. Clearly, in three-way and higher-order interactions, a plethora of combinations of local adaptation, local maladaptation and absence of adaptation among these different players is possible.

\section{MOLECULAR AND PHYLOGENETIC PATTERNS OF DIVERGENCE IN THREE-WAY INTERACTIONS}

Like in two-way interactions, studies using contemporary variation and selection in three-way interactions, as described above, may fail to recognize the importance of such interspecific interactions in shaping evolutionary or co-evolutionary diversification and adaptation. This is because the genetic variation in traits of one or more species that were initially involved in evolutionary diversification may have become fixed at the species or even higher taxonomic level over evolutionary time. For instance, acquisition of microbial symbionts that provide nutritional or defensive benefits to their arthropod hosts could enable these arthropod hosts to shift onto novel host plants and alter plant-mediated selection, contributing to plant-associated diversification and adaptation (Janson et al. 2008). However, much of the variation in the traits that contributed to plant-associated diversification at the time that the symbionts were acquired by the arthropod may now have become fixed within species as a result of selection and drift. Molecular studies tracing divergence of arthropod lineages on different host plants following acquisition of symbionts and co-divergence among arthropod and symbionts on different plant species could then be helpful to 
(a)

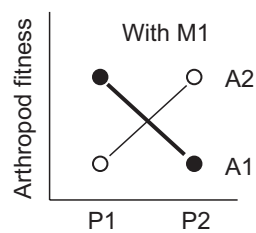

(b)

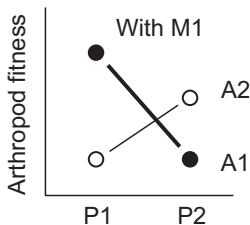

(c)

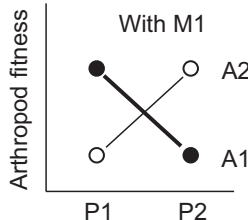

(d)

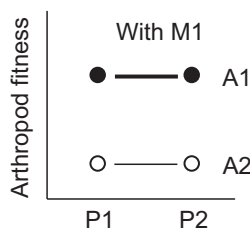

(e)

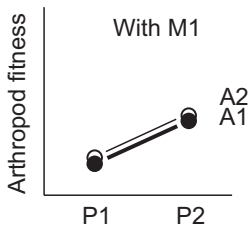

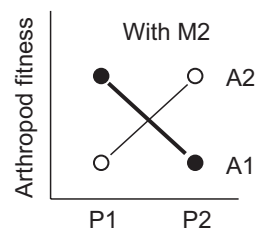
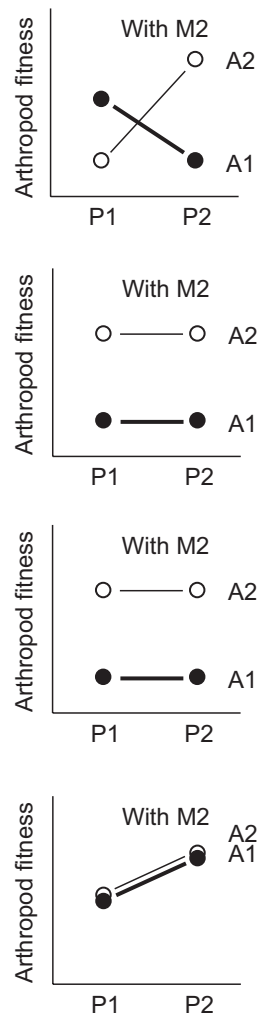

Fig. 2. Hypothetical examples of patterns of local adaptation in plant-microbe-arthropod interactions, exemplified by arthropod local adaptation in a three-way interaction between a plant, arthropod and plant-associated microbe. Graphs display fitness of arthropod genotypes (A1, black circles; A2, open circles; subscripts 1 and 2 refer to population origin) on genotypes of food plants from their local populations (P1 and P2, respectively) and non-local populations, in the presence of genotypes of plant-associated microbes from their local populations (M1 and M2, respectively, left and right panels) and non-local populations. (a) Arthropod local adaptation to food plants independent of their microbes; (b) arthropod adaptation to the local combination of food plant and microbe; (c) arthropod local adaptation to plants depends on the microbial associate of the plant; (d) arthropod local adaptation to the plant's local microbial associate, independent of the plant itself; (e) no arthropod local adaptation; arthropods perform uniformly better on host plants and plant-associated microbes from population 2 .

infer a role of three-way interaction in evolutionary diversification and adaptation.

\section{THE EVOLUTIONARY IMPLICATIONS OF PLANT-MICROBE-ARTHROPOD INTERACTIONS}

In this perspective, we place plant-microbe-arthropod interactions within an evolutionary framework. (1) We first synthesize the emerging evidence that each of the players (plants, microbes and arthropods) can affect the evolutionary interactions between the other two players. To this end, we have surveyed the literature for studies from a wide array of systems that demonstrate (i) heritable variation in the outcome of three-way interactions as well as evolutionary responses to selection and local adaptation in three-way interactions, as revealed by artificial selection and local adaptation studies, and (ii) evolutionary patterns of divergence signifying a role of three-way interactions in evolutionary diversification and adaptation as revealed by molecular and phylogenetic studies. (2) We then synthesize these results, outline the gaps in our current knowledge and pinpoint promising directions for further research. For convenience, we have somewhat artificially subdivided the first part into three separate sections (Fig. 1 arrows 4, 5 and 6): microbial mediation of plant-arthropod interactions, plant mediation of arthropod-microbe interactions and arthropod mediation of plant-microbe interactions.

\section{Microbial mediation of plant-arthropod interactions}

\section{MEDIATION OF PLANT-ARTHROPOD INTERACTIONS BY PLANT-ASSOCIATED MICROBES}

Plants are associated with a vast array of microbes with either beneficial or detrimental effects on their performance. These include root-associated micro-organisms like mycorrhizae, rhizobia, plant growth-promoting rhizobacteria or fungi, root endophytes, soil pathogens and decomposers, as well as a wide variety of beneficial and pathogenic fungi, bacteria, viruses and other micro-organisms that are associated with above-ground plant parts. These micro-organisms can cause significant phenotypic changes (phenological, morphological, physiological or biochemical) in their host plants and select for plant traits involved in these plant-microbe interactions, which subsequently affect their attractiveness and suitability (phenology, size, nutritional and defence status) as host plant for arthropods, including herbivores, disease vectors, pollinators and carnivores. Arthropods show various non-evolutionary and evolutionary responses to these microbially mediated changes. Below, we summarize some of these responses and observed adaptation of arthropods to microbially induced changes in their host plant.

\section{Heritable variation, selection and local adaptation}

Several studies have shown heritable variation in the performance of arthropods on particular combinations of host plants and associated microbes that can facilitate evolutionary adaptation. Tétard-Jones et al. (2007) showed that the presence of a growth-promoting rhizobacterium, Pseudomonas aeruginosa, alters the interactions between barley (Hordeum vulgare) genotypes and strains of the grain aphid Sitobion avenae $\left(\mathrm{G}_{\mathrm{A}} \times \mathrm{G}_{\mathrm{P}} \times \mathrm{E}_{\mathrm{M}}\right.$, see Table 1). The presence of the rhizobacterium either 

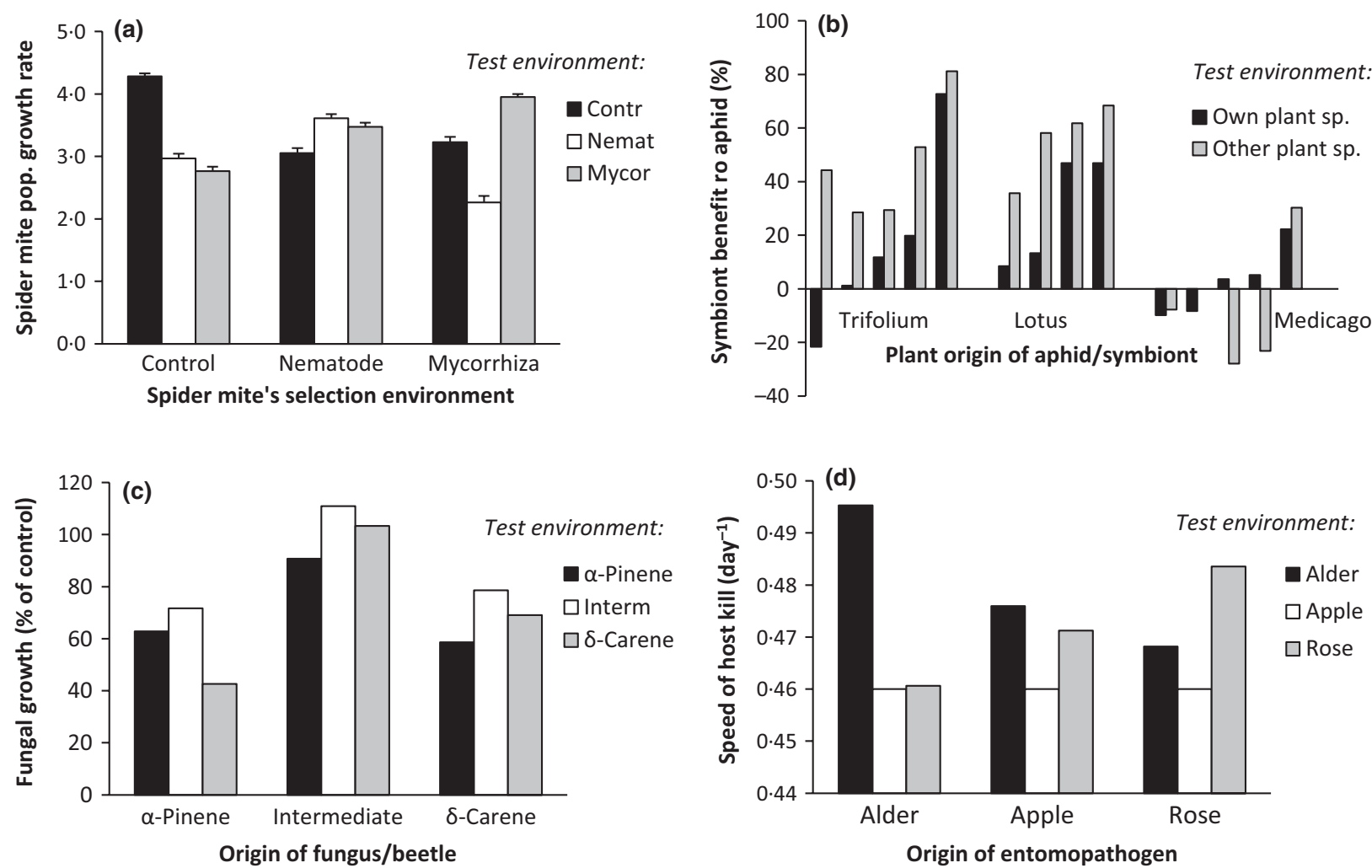

Fig. 3. Examples of studies of adaptation in three-way interactions between plants, microbes and arthropods. (a) Adaptation of arthropods to host plant phenotypes induced by soil biota (after Bonte et al. 2010). Spider mites (Tetranychus urticae) selected for 15 generations on common bean (Phaseolus vulgaris) plants have higher population growth rates on plants with the specific soil biota (mycorrhiza, Glomus mosseae, or nematodes, Pratylenchus penetrans) that they experienced during selection than on plants without these soil biota. (b) Lack of adaptation of insect/endosymbiont combinations to the food plant species from which they originate (after McLean et al. 2011). Pea aphid clones (Acyrthosiphon pisum) do not enjoy higher reproductive benefit from their facultative endosymbionts (Hamiltonella defensa or Regiella insecticola) on the host plant species from which they originate (white clover, Trifolium repens, great bird's foot trefoil, Lotus pedunculatus, or alfalfa, Medicago sativa) than on another host plant (broad bean, Vicia faba). On the contrary, the benefit to aphid clones from Trifolium and Lotus is consistently lower on their 'home' plant species. Data were recalculated from Fig. S1 as 100*(S-NS)/ (S) where S and NS are the \# offspring of aphids with symbionts and aphids from which symbionts were removed, respectively. (c) Lack of adaptation of nutritional symbiotic fungi to the host plant chemotype from which their vectoring insects originate (after Davis \& Hofstetter 2012). Strains of the nutritional mutualist fungus Entomocorticum $s p$. B, that is vectored and inoculated in their galleries by western pine bark beetles (Dendroctonus brevicomis), do not perform best on diets representing the monoterpene chemotype of the host tree (Ponderosa pine, Pinus ponderosa) from which the beetles originated. Fungi isolated from beetles originating from the two more extreme chemotypes, dominated by $\alpha$-pinene and delta-3-carene, respectively, tend to grow better on media mimicking their own chemotype than on the other extreme chemotype, but both grow better on diets mimicking a third, less extreme, intermediate chemotype. (d) Partial adaptation of entomopathogens to insect host phenotypes induced by their food plants (after Cory \& Myers 2004). Strains of the nucleopolyhedrovirus (McplNPV) of western tent caterpillars (Malacosoma californicum pluviale) originating from Canadian Islands dominated by red alder (Alnus rubra) and wild rose (Rosa nutkana) kill their host caterpillars most quickly when hosts feed on these host plants, but the pattern is not observed for strains from apple (Pyrus malus). Data were recalculated from Fig. 1 as 1/rate of kill at a standardized virus dose of 316 occlusion bodies per larva.

increased or decreased the performance of the aphids, depending on the combination of barley and aphid genotype. Further studies identified five barley quantitative trait loci (QTL) affecting aphid population growth of which the expression was altered by the rhizobacterium (TétardJones, Kertesz \& Preziosi 2012), providing unique insight into the genetics underlying variation in plant-mediated interactions between microbes and arthropods. Differential responses of arthropods to the microbial extension of their host plants have also been observed for arthropods feeding on grasses that differ either in the presence or absence, or in the particular strains of associated clavicipitaceous endophytes (Class I, sensu Rodriguez et al. 2009) that they harbour. These endophytes produce alkaloids that generally reduce arthropod performance (defensive mutualism, see upcoming special feature edited by Keith Clay). However, their effects often vary among genotypes within herbivore species. For instance, while most clones of the bird cherry-oat aphid (Rhopalosiphum padi) perform better on tall fescue (Lolium arundinaceum) when it is endophyte-free, some perform better when this host is infected by a strain of Neotyphodium coenophialum $\left(\mathrm{G}_{\mathrm{A}} \times \mathrm{E}_{\mathrm{M}}\right.$, see Table 1) (Bieri et al. 2009). The response of the herbivore is further contingent upon host plant genotype (Bultman et al. 2006) and the specific endophyte strain associated with the host plant (Bultman et al. 2009). 
Interestingly, densities of the fall armyworm (Spodoptera frugiperda) were less impacted by a novel strain of $N$. coenophialum than by a common strain (Bultman, Aguilera \& Sullivan 2012), which might indicate some adaptation of the arthropods to the common strain.

While all these studies clearly show the potential for microbially mediated selection and adaptation in the plant-arthropod interaction, few have actually documented such evolutionary processes. One of the most convincing studies showing that arthropods can evolutionarily respond to selection mediated by plant-associated microbes and adapt to the plant's local microbial associate is that by Bonte et al. (2010) (Fig. 3a). In an artificial selection experiment, they raised spider mites (Tetranychus urticae) originating from a large, genetically diverse base population for 15 generations on common bean plants (Phaseolus vulgaris). The plants were consistently grown under one of three specific soil biota conditions: (i) presence of mycorrhizae (Glomus mosseae); (ii) presence of plant parasitic nematodes (Pratylenchus penetrans) or (iii) control plants without these soil biota. After 15 generations of selection, spider mites selected in the presence of mycorrhizae or nematodes had significantly higher population growth rates on plants inoculated with these soil biota than on control plants and vice versa. This indicates adaptation of the arthropods to the phenotypes of their host plant that were induced by the presence of their local soil biota $\left(G_{A} \times E_{M}\right.$, Table 1). This study importantly shows, first, that there was genetic variation in the response of the spider mites to microbially induced phenotypic variation in their host plants and, second, that the effect of the microbially induced phenotype was large and consistent enough across generations to result in directional selection within the spider mite population.

Arthropods also commonly show innate and/or learned behavioural responses to microbially induced changes in their host plants that result in altered visitation, oviposition or feeding rates (e.g. Hatcher 1995; Stout, Thaler \& Thomma 2006). Often, these behavioural responses are adaptive, that is, they either result in better exploitation of positive effects of microbially induced changes on plant quality (e.g. Jallow, Dugassa-Gobena \& Vidal 2008) or negate the negative effects of the induced changes on plant quality (e.g. Biere et al. 2002; Biere \& Honders 2006; but see, e.g., Bosque-Pérez \& Eigenbrode 2011). Such behavioural adaptations can even be specific to the pathogen strain associated with the plant (e.g. Cardoza \& Tumlinson 2006). Behavioural responses are not only important because they can provide a direct selective advantage, but also because they can allow arthropods to perform sufficiently well on microbially infected plants to create a window of opportunity for genetic adaptation to occur. In some cases, these behavioural adaptations may have been co-opted by the arthropod from behaviours evolved in response to other biotic or abiotic selection pressures that result in similar phenotypic changes in its host plant (exaptations, sensu Gould \& Vrba 1982). Regardless, it would be interesting to see whether there is contemporary intraspecific genetic variation in the extent or pattern of arthropod behavioural responses to microbially induced changes in plant phenotypes, which could facilitate evolutionary fine-tuning of the behaviour in response to microbially mediated selection. Surprisingly, such intraspecific variation has been seldom reported. It is therefore still an open question whether these behavioural responses are generally fixed at the species level or that this type of variation exists but has rarely been explored.

\section{Longer-term evolutionary patterns}

There has been recent speculation that the evolved behavioural responses of arthropods to microbially induced changes in the host plant are exploited by microbes that rely on these arthropods for their transmission by manipulating the plant cues to which the arthropods respond (Mauck, De Moraes \& Mescher 2010; Mann et al. 2012; McMenemy et al. 2012; Mauck et al. 2012). Many arthropods are important vectors of plant viruses. The evolutionary interactions between plant, virus and vector are complex (Blanc, Uzest \& Drucker 2011). Viruses have evolved intricate ways to hijack and exploit host plant metabolic, defence and other pathways (LozanoDuran et al. 2011; Gutierrez et al. 2013) to alter the attraction, the propensity to initiate sustained feeding and the performance of their insect vectors in ways that can increase their transmission (e.g. Stafford, Walker \& Ullman 2011). Interestingly, there is increasing evidence that viruses with different transmission modes differ in the way that they modulate their host plant's phenotype and that the specific pattern of modulation triggers behavioural responses in their insect vectors that match the virus' requirement for effective transmission (Mauck et al. 2012). Specifically, all viruses are expected to increase the attractiveness of host plants to insect vectors. But only viruses with a persistent transmission mode, which require sustained feeding by the vector for effective transmission, are expected to enhance the quality of the plant as a resource for the vector and to enhance plant traits that promote the propensity of vectors to settle and feed. By contrast, for viruses with a non-persistent transmission mode, which can be quickly acquired by their vectors, it would be more beneficial to affect plant traits that do not encourage prolonged feeding, but instead encourage their immediate dispersal to uninfected host plants to speed up transmission. Several studies support these ideas (reviewed in Mauck et al. 2012), suggesting that the distinct patterns of how viruses manipulate the plant mechanisms that underlie their interactions with vectoring arthropods have evolved in parallel with the distinct specialized transmission modes of these viruses (adaptive parasite manipulation, Poulin 1995; Lefevre \& Thomas 2008). This illustrates not only the pervasive role that microbes can play in determining 
the outcome of plant-arthropod interactions, but also the complexity of interspecific feedbacks involved in the evolution of virus transmission modes.

\section{MEDIATION OF PLANT-ARTHROPOD INTERACTIONS BY ARTHROPOD-ASSOCIATED MICROBES}

Arthropods are associated with a wide variety of microorganisms. These include viral, fungal and bacterial entomopathogens as well as endo- or ectosymbionts that can play important ecological roles in nutrient provisioning, food plant exploitation, defence against natural enemies and stress tolerance of the arthropods. Much of our current insight into the role of arthropod-associated microbes as mediators of evolution in plant-arthropod interactions comes from studies of obligate and facultative endosymbionts of phloem- and xylem-feeding arthropods that have addressed their role in the evolution of food plant use and specialization of their arthropod hosts. Obligate (primary) endosymbionts are vital for survival and reproduction of their hosts. They are often located in special organs such as bacteriomes or midgut crypts and are predominantly vertically (maternally) transmitted. Hence, they become part of the heritable genetic variation of their hosts, sometimes referred to as the holosymbiont (Feldhaar 2011). Acquisition of these symbionts is often followed by an evolutionary process of complementary and irreversible gene loss in host and symbiont and extreme genome reduction on the side of the symbiont. Facultative (secondary) endosymbionts, on the other hand, are not indispensable for arthropod survival and reproduction. Although heritable, they are often not strictly vertically transmitted, and they provide benefits that are conditional on abiotic and biotic environmental conditions. Janson et al. (2008) distinguished two processes by which microbial endosymbionts of arthropods could affect the evolution of food plant use and food plant-associated differentiation of their hosts. The first is through extension of the arthropod's phenotype in terms of nutritional, defensive or stress tolerance abilities, thereby enhancing (or, theoretically, reducing) the arthropod's ability to exploit novel host plants ('ecological opportunity'). The second is through altering food plantassociated selection, that is, favouring high performance of the arthropod on some plants but not on others ('modulating selection'). In this section, we will first discuss evolutionary patterns that strongly suggest a prominent role of primary endosymbionts in enhancing the ecological opportunity of arthropods. Thereafter, we will discuss the role of primary endosymbionts, secondary endosymbionts and ectosymbionts in modulating host plant-associated selection, using studies of heritable variation, selection and local adaptation. These studies will show that the benefits of all these symbionts to the arthropods are indeed often host plant specific, but seldom provide higher benefit on the local host plant of the arthropod. Finally, this section will discuss the impact of entomopathogens on host plant adaptation in arthropods.

\section{Primary endosymbionts}

There is no doubt that the evolution of a phloem- or xylem-feeding strategy by arthropods was facilitated by the acquisition of endosymbionts that contributed to the provisioning of the essential amino acids and vitamins that lacked from these imbalanced host plant resources and that could not be synthesized by the arthropods themselves (Douglas 1998). For instance, in sharpshooters, a subfamily of leafhoppers feeding on xylem sap, phylogenetic analyses indicate that the shift to xylem sap feeding occurred shortly after they acquired the obligate bacterial nutritional endosymbiont, Baumannia cicadellinicola (Takiya et al. 2006). After that, hosts and endosymbionts diversified in parallel. Much earlier, the acquisition of another endosymbiont, Sulcia muelleri, had enabled their ancestors to adopt a general sap-feeding lifestyle on primitive vascular plants (Takiya et al. 2006). Thus, the initial acquisition of obligate endosymbionts was probably responsible for a major innovation in arthropods that broadened their ecological niche and enabled them to utilize novel resources. Further support that endosymbionts can enhance their host's opportunities for exploitation and utilization of novel host plants comes from a number of elegant endosymbiont manipulation studies (e.g. Hosokawa et al. 2007; Tsuchida et al. 2011) that clearly illustrate enhancement of ecological opportunity by acquisition of endosymbionts, even though in nature such horizontal transfer events may be extremely rare (Oliver et al. 2010), especially for obligate endosymbionts.

In contrast to the strong support for a role of primary endosymbionts in increasing ecological opportunity, there seems to be far less support for an important role of these endosymbionts as modulators of host plant-associated selection in ways that shape contemporary patterns of host plant use and adaptation of their phloem- and xylem-feeding arthropod hosts. This is best illustrated by recent results from the intensively studied system of pea aphids (Acyrthosiphon pisum) and their obligate and facultative endosymbionts. Pea aphids form a series of genetically differentiated, food plant-associated populations, connected by varying degrees of gene flow. The clones show tradeoffs in performance on different host species and exhibit a strong pattern of local adaptation to their preferred host plant species (Via 1991; Ferrari, Via \& Godfray 2008; Peccoud et al. 2009). The role of endosymbionts in the observed patterns of host plant-associated differentiation and adaptation of pea aphids has long been enigmatic. Pea aphids partly rely on their obligate endosymbiont Buchnera aphidicola for the synthesis of essential amino acids that are not, or insufficiently, provided by the phloem of their leguminous host plants. Interestingly, combinations of pea aphid clones and their Buchnera symbionts differ in their requirements of dietary essential amino acids, the so-called nutritional phenotype of the symbiosis. Some aphid clones are relatively independent of the provisioning of essential amino acids in their diet, whereas others require several of 
them for growth and reproduction (Douglas 1998). Therefore, we could argue that if variation in the nutritional phenotype of the symbiosis is largely explained by variation in the nutritional capacities of the endosymbiont, the endosymbiont could also potentially play an important role in the observed host plant-associated differentiation and adaptation.

Surprisingly, recent molecular and metabolic modelling studies do not support an important role of the endosymbiont in explaining the nutritional phenotype. It had been anticipated that functional variation in Buchnera genes involved in the biosynthesis of essential amino acids would be an important source of variation in nutritional phenotypes and partly represent endosymbiont adaptation to host plant variation in the provisioning of amino acids and their precursors. However, first, analyses of the genomes of Buchnera (Shigenobu et al. 2000) and pea aphids (Wilson et al. 2010) unexpectedly revealed that the biosynthesis of several of the essential amino acids is not simply mediated by symbiont genes, but requires an intimate collaboration between pea aphid and symbiont genes (Hansen \& Moran 2011). This is because the aphid and symbiont have experienced strong, even within-pathway, complementary loss of functional genes involved in the biosynthesis of essential amino acids over evolutionary time, thus requiring coordinated action of aphid and symbiont to produce them (Hansen \& Moran 2011). Second, while a number of studies have indeed found functional sequence variation in genes involved in the endosymbiont-mediated steps of amino acid biosynthesis in at least some Buchnera strains in some aphid clones (Wernegreen \& Moran 2000; Moran \& Degnan 2006; Vogel \& Moran 2011), this variation does not appear to be a dominant factor in explaining overall variation in nutritional phenotypes. Instead, an elegant metabolic modelling study by MacDonald, Thomas \& Douglas (2011) revealed that variation in nutritional phenotypes can be largely explained by aphid variation in the provisioning of nutrient precursors necessary for the steps in the essential amino acid biosynthesis that are mediated by the endosymbiont. In other words, not the symbiont but the aphid appears to be in control of the nutritional phenotype and may regulate their joint metabolic pathways depending on the host plant species with which they are associated. Overall, these data thus do not provide convincing support that Buchnera has been an important driver of the current pattern of host plant use and adaptation in pea aphids by incurring selective advantages or disadvantages on specific host plants due to variation in its potential to provide essential amino acids to its aphid hosts.

\section{Secondary endosymbionts}

In contrast to the obligate endosymbionts discussed above, facultative endosymbionts of pea aphids are not indispensible for survival and growth and have been experimentally manipulated to study their role in host plant-associated differentiation and in the current patterns of host plant use and local adaptation in pea aphids. Remarkably, this had led to the same conclusion as above, that is, that they provide benefits that are conditional on host plant, but do not generally increase their host's fitness specifically on the food plant that they are specialized on. Pea aphids harbour several secondary endosymbionts. The prevalence of these secondary endosymbiont species strongly differs among aphid clones specialized on different plant species (Simon et al. 2003; Ferrari et al. 2012). However, while such non-random distribution patterns of secondary symbionts are interesting, they do not tell us whether they are a cause or a consequence of the divergence of pea aphids on different host plant species. The co-association may be observed either because particular aphid-endosymbiont combinations perform best on particular host plants or simply because aphids specialized on different host plant species tend to get associated with different assemblages of facultative endosymbionts.

Recent experimental manipulation studies have specifically tested (i) whether benefits provided by secondary endosymbionts are host plant specific, and hence could modulate selection on host plant use in their aphid hosts; and (ii) whether any benefits that aphids gain from their local endosymbionts is higher on the host plant species on which they are specialized than on any other plant species, suggesting local adaptation. While evidence for the former is strong, there appears to be no general evidence for the latter. Initial studies showed that removing the dominant endosymbiont Regiella aphidicola from an aphid clone specialized on clover reduced the performance of this aphid specifically on its local host plant, clover, but not on Vicia faba, a general host plant that is widely accepted by pea aphids (Tsuchida, Koga \& Fukatsu 2004). This supports the idea that the benefit of the local endosymbiont is largest on the food plant that the aphid is specialized on. However, removal of $R$. aphidicola from two other aphid clones specialized on clover did not reduce their performance on this host plant (Leonardo 2004), and introduction of $R$. aphidicola strains into $R$. aphidicola-free aphid clones had inconsistent effects on their performance on clover (Ferrari, Scarborough \& Godfray 2007). In even more striking contrast to the findings by Tsuchida, Koga \& Fukatsu (2004) are recent studies by McLean et al. (2011). They showed that removal of endosymbionts from pea aphid clones specialized on clover generally leads to a clone-specific reduction in aphid performance on clover. Thus, aphid clones benefit, to different extent, from the presence of their associated endosymbionts on their local host plant. However, in sharp contrast to the idea that the assemblage of co-transmitted secondary endosymbionts specifically benefits the aphids in exploiting the local host plant on which they are specialized, the benefit of these associated symbionts appeared to be consistently higher on the non-local host plant $V$. faba (Fig. 3b). The same was true for aphids specialized on Lotus, whereas aphids from three other host plants suffered as much from 
endosymbiont removal on their local host plant as on $V$. faba. This strengthens the conclusion that secondary endosymbionts can modulate food plant-associated selection by providing host plant-dependent benefits, but also suggest that they have not played a major role in the observed local adaptation of the aphids to their food plants, given the lack of specific benefits on the host plants on which the aphids are specialized. Based on additional studies, Ferrari et al. (2012) concluded that the host plantassociated distribution of secondary symbionts in the pea aphid complex is more likely a consequence than a cause of the host plant-associated divergence of their pea aphid hosts (Ferrari et al. 2012). This does not rule out that secondary endosymbionts could be involved in patterns of adaptation at a finer scale (below the plant species level), which would require studies involving plants, aphids and endosymbionts from local and non-local populations.

\section{Ectosymbionts}

A few groups of arthropods form symbioses with plantfeeding fungi that they farm in fungal gardens. These fungi are inoculated and grown on food sources that they can break down more efficiently than the arthropods, enabling the arthropods to extend the range of food sources that the arthropods can exploit. Therefore, they are often considered as nutritional ectosymbionts. Few studies in these systems have investigated the question that was posed earlier for endosymbionts, that is, whether the benefits that these fungi provide to their arthropod hosts are highest on the local food plant of the arthropod. Davis \& Hofstetter (2012) did not find strong evidence for such local adaptation (Fig. 3c). They studied the performance of strains of a fungal nutritional symbiont (Entomocorticium $s p$.) farmed by western pine bark beetles (Dendroctonus brevicomis) on local versus non-local host plant chemotypes of ponderosa pine (Pinus ponderosa). During colonization of pine trees, the adult beetles inoculate tree vascular tissues with fungal mycelia that they carry in special exoskeletal fungal transport structures (mycangia). The fungi themselves are considered to be non-pathogenic and harmless to the trees, but beetle larvae feed on the fungal mycelia in vascular tissues, creating galleries that usually result in tree death. Ponderosa pine populations in northern Arizona are polymorphic for oleoresin chemotype. A few chemotypes can be distinguished based on oleoresin monoterpene composition, predominantly those dominated by (i) alpha-pinene; (ii) delta-3-carene and (iii) a chemotype with intermediate concentrations of both of these monoterpenes. Fungi isolated from beetles collected from these three chemotypes were reciprocally grown on media amended with monoterpene mixtures that closely mimicked these chemotypes. Control media without monoterpenes were included to assess the growth reduction experienced on each of the monoterpene mixtures. Contrary to expectations based on a general pattern of local adaptation, fungi did not perform best on the mixture representing the tree chemotype from which their beetle host had been collected. Instead, they performed best on the mixture representing the intermediate chemotype, irrespective of their origin, suggesting that more extreme chemotypes may be more challenging to the fungus. Moreover, fungi originating from beetles collected from the intermediate tree chemotype tended to outperform fungi isolated from beetles collected from the two more extreme tree chemotypes on all media (Fig. 3c). The results suggest that chemotypic variation in plants does exert selection on mutualistic nutritional microbes of bark beetles, affecting arthropod performance, but that such selection has not resulted in bark beetles farming nutritional microbes best adapted to exploit the tree chemotypes of their current choice.

By contrast, some studies of longer-term evolutionary patterns do provide some support to the idea that fungi domesticated by arthropods adapt to the host plants of their arthropods (Semenova et al. 2011). Attine ants rear basidiomycete fungi on a substrate consisting of plant material that they collect in fungal gardens. The fungi break down the plant material using proteinases, making nitrogen more easily available to the ants. Semenova et al. (2011) showed that the proteinase activity of fungi associated with lower attine ants is dominated by metalloproteinases, whereas that of fungi tended by higher, more derived, attine ants, that have no known free-living fungal relatives, is dominated by serine proteinases. The latter have a higher enzyme activity, a pH optimum that is much closer to that of the gardens and more buffering capacity at this $\mathrm{pH}$ than the former. This suggests that the irreversible domestication of these fungi by attine ants on their particular plant substrates has been instrumental in the evolution of the fungal proteinases, increasing the benefit of these symbionts to their tending arthropods. Interestingly, there is also support for an alternative way of increasing the benefits of fungal symbionts, namely by arthropods adjusting their food plant choice to match the current abilities of their tended fungi (Saverschek et al. 2010).

\section{Entomopathogens}

Not only symbionts, discussed above, but also entomopathogens can affect host plant-associated selection in their arthropod hosts. For instance, entomopathogens can affect the rate of evolution of resistance of arthropods to host plant defences (Gould, Kennedy \& Johnson 1991). A study by Johnson, Gould \& Kennedy (1997) showed that entomopathogens accelerated the rate of adaptation of the tobacco budworm (Heliothis virescens) to transgenic tobacco plants that contained sublethal concentrations of the Bacillus thuringiensis $(B t)$ toxin. During 8-10 generations of selection, the arthropod adapted quicker to $B t$ tobacco in the presence of the fungal entomopathogen Nomuraea rileyi than in its absence (Johnson, Gould \& Kennedy 1997). Larvae of the budworm that were slightly more adapted to $B t$ were less inclined to move immediately 
to another plant in search of less toxic food, thereby reducing their encounter rate with the entomopathogen. This in turn reduced their entomopathogen-induced mortality and enhanced their fitness advantage over less adapted larvae, speeding up selection. Interestingly, whereas the presence of the fungus affected the arthropod's rate of adaptation to the plant (a three-way interaction), it did not result in any adaptation of the arthropod to the fungus (a direct, two-way interaction) on a given plant.

\section{Plant mediation of arthropod-microbe interactions}

\section{PLANT-MEDIATED SELECTION IN \\ ARTHROPOD-ENTOMOPATHOGEN INTERACTIONS}

Previously, we have seen how entomopathogens can affect selection in plant-arthropod interactions. Conversely, plants can have a large impact on selection in arthropod-entomopathogen interactions. Entomopathogens are a diverse group of organisms that include fungi, bacteria and viruses, predominantly nucleopolyhedroviruses (NPVs) and other baculoviruses. Many studies have illustrated the importance of bottom-up (plant-mediated) effects in interactions between arthropods and their entomopathogens (Duetting et al. 2003; Raymond \& Hails 2007; Shikano et al. 2010), and plants have been shown to affect entomopathogens either directly or indirectly (i.e. mediated by the arthropod) (reviewed in Cory \& Hoover 2006; Cory \& Ericsson 2010). Most studies documenting that variation in plant attributes can affect arthropodentomopathogen interactions are based on effects of plant interspecific variation. For example, entomopathogens show genetic variation in their response to interspecific variation in the food plants of their herbivores (Hodgson et al. 2002). This could lead to adaptation of entomopathogens to the local food plant species of their herbivorous hosts, as suggested by a study of Cory \& Myers (2004). They showed that entomopathogens kill off their arthropod hosts faster when these are reared on the host plant with which they had a co-evolutionary history than on other host plants (Fig. 3d). Strains of the nucleopolyhedrovirus ( $M c p l \mathrm{NPV}$ ) of western tent caterpillars (Malacosoma californicum pluviale) were collected from three distinct island populations in the southern Gulf Islands in Haro Strait, Canada. The islands were dominated by red alder (Alnus rubra), wild rose (Rosa nutkana) and apple (Pyrus malus), respectively. The first two represented stable populations of tent caterpillars, whereas populations on the apple-dominated island were characterized by frequent extinctions and recolonizations from adjacent islands that could be dominated by other food plants than apple. NPV performance was tested on caterpillars that were fed either the dominant food plant species at the NPV's site of origin (local food plant) or the two non-local food plants (Fig. 3d). As expected based on a scenario of adaptation to the local food plants of their caterpillars, NPV strains from the stable populations (islands dominated by red alder and rose) had the highest speed of kill when their hosts were reared on the plant species that corresponded to the locally most dominant food plant at the NPV's origin. This pattern was not observed for the strains originating from the non-stable populations that probably experienced different host plants during their recent evolutionary history. Obviously, speed of kill is only one aspect of virus fitness; virus isolates did not differ in pathogenicity (virus-induced mortality), and relationships between speed of kill and virus yield differed among isolates. Yet, for speed of kill, the results suggest that entomopathogens can adapt to the local food plants of their hosts with which they have a co-evolutionary history. It should be noted that the design of the above-mentioned study puts some important limitations to the interpretation of the results in the context of local adaptation, which are exemplary for studies of adaptation in more complex interactions. Virus isolates from each population were pooled per island, and hence, within-island replication was essentially lost, preventing us to draw conclusions at the population level that are required for inferences about general patterns of local adaptation. Also, the herbivores were collected from a common source that was non-native to all islands, so that any evolved responses of herbivores to their local food plants that would affect their phenotype as experienced by the virus is taken out of the interaction. There are obviously good reasons for such design limitations; the size of full factorial experiments quickly increases beyond the experimenter's abilities. Yet, these limitations are a main constraint to our current insight into patterns of more complex local adaptation.

Entomopathogen adaptation to the local host plant of arthropods has experimentally been observed for nonmicrobial entomopathogens using artificial selection studies (Barbercheck, Wang \& Brownie 2003). However, not all studies show indications of local adaptation of entomopathogens to the food plant of their arthropod hosts. For example, Raymond et al. (2002) found no evidence that the NPV of the winter moth, Operophtera brumata, from oak (Quercus robur) and Sitka spruce (Picea sitchensis), had higher rates of host kill or virus yield on the host plant species from which they originated. Another promising system for studying evolutionary effects of host plants on arthropod-pathogen interactions revolves around the interaction between the protozoan parasite Ophryocystis elektroscirrha and its monarch butterfly host Danaus plexippus. This interaction is strongly affected by the chemical composition of their milkweed host plants, and it was shown that host plant variation can drive virulence evolution in the arthropod's parasite (de Roode et al. 2011).

Several studies have shown that arthropod-entomopathogen interactions can also be modulated by extant intraspecific genetic variation in plants. For instance, mulberry genotypes (Morus spp.) differ in their effects on NPV efficacy in the silk worm Bombyx mori (Sosagomez, Alves \& Marchini 1991). Furthermore, chickpea (Cicer 
arietinum) genotypes differ in their effects on NPV efficacy as mortality factor in the cotton bollworm Helicoverpa armigera (Cowgill \& Bhagwat 1996). This indicates the opportunity for reciprocal evolutionary interactions between plants and entomopathogens of their arthropods.

\section{ENTOMOPATHOGENS AS PLANT BODYGUARDS}

The observation that host plant attributes can have strong direct and indirect effects on the encounter rate and susceptibility of herbivorous arthropods to their entomopathogens has also repeatedly inspired the question whether such plant attributes evolved, at least partly, in response to these biotic interactions and whether these traits can be considered as an indirect defence strategy by which plants recruit entomopathogens as bodyguards against herbivorous arthropods (Elliot et al. 2000; van Munster et al. 2005; Cory \& Hoover 2006; Cory \& Ericsson 2010). This is analogous to the long-standing question whether plants use herbivore-induced volatile organic compounds as an indirect defence strategy to attract parasitoids and predators as bodyguards against herbivores (Dicke \& Sabelis 1988; Turlings et al. 1995; van der Meijden \& Klinkhamer 2000; Allison \& Hare 2009) and whether under stressful conditions plants can attract rhizobacteria to trigger a priming response that enhances their defence against herbivore attacks (Pineda et al. 2013). In evolutionary terms, the crucial question is whether there is heritable variation in plant traits that consistently increase the efficiency of entomopathogens in reducing plant feeding by herbivorous arthropods and whether that indeed results in increased plant fitness. Unfortunately, despite the clear demonstration of effects of plant traits on entomopathogen efficacy and of evolutionary responses of entomopathogens to the local food plants of their hosts, crucial pieces of evidence for their benefits to the host plant are even more scant than for the hypothesis that plant volatiles can be seen as an indirect defence strategy by which plants recruit arthropod natural enemies as bodyguards. Notably, studies often fail to show consistent numerical or functional responses of herbivorous arthropods to entomopathogens in response to host plant variation, and effects on plant fitness have rarely been addressed (Cory \& Ericsson 2010). This hypothesis therefore awaits further study.

\section{Arthropod mediation of plant-microbe interactions}

While many studies have investigated whether and how microbes alter selection on arthropods by modulating plant-arthropod interactions, only few have, conversely, addressed the question whether arthropods exert indirect selection on microbes by modulating plant-microbe interactions. Two types of studies have illustrated the role of arthropods in modulating selection in plant-microbe interactions. First, studies of plant virus-vector interactions have recently addressed the impact of variation in the behaviour of the vectoring arthropod on plant virus evolution. For instance, different plant-feeding strategies among insect vectors can have major implications for the evolution of plant viruses by enhancing or reducing their opportunities for recombination. These issues are addressed by Gutierrez et al. (2013) in this issue. A second type of studies involves indirect effects of arthropods on microbes in the plant's rhizosphere. Rhizosphere microbial communities can adapt to the specific plant species and genotypes that they are associated with (Schweitzer et al. 2008). For instance, soil microbial communities are often better at decomposing litter from plant species that are native to that soil microbial community than litter from foreign plants (the so-called home field advantage, Gholz et al. 2000). Such microbial adaptation has been observed both at the level of plant species and at the level of individual plant genotypes (Madritch \& Lindroth 2011). In turn, the plant-mediated changes in soil microbial community can positively feed back on plant genotype fitness through, for example, benefits of increased local mineralization (Smith et al. 2012). Interestingly, recent studies have shown that herbivorous arthropods can modulate these plant-soil microbe interactions. Herbivorous arthropods alter plant tissue quality, thereby affecting soil microbial communities through altered root exudation profiles and litter quality (e.g. Madritch, Donaldson \& Lindroth 2007; Hamilton et al. 2008). Arthropods thus exert selection on the rhizosphere microbial community through altering properties of their host plants. Studies by Kostenko et al. (2012) suggest that such arthropod-mediated selection creates a soil legacy effect that can affect the fitness of both the plant's offspring and the arthropod's offspring. Shoot herbivory by the noctuid Mamestra brassicae altered the rhizosphere fungal community of ragwort (Jacobaea vulgaris). This created a soil legacy effect: ragwort offspring exposed to soil inoculated with the altered soil biota originating from the rhizosphere of the mother plant produced less root biomass and had lower levels of shoot secondary metabolites (pyrrolizidine alkaloids), which interestingly supported higher growth rates of Mamestra larvae in the next generation. Not all studies of arthropod effects on plant-soil microbe interactions provide evidence that arthropods can modulate selection in these interactions. For instance, after twenty years of experimental removal of the stem-boring moth, Dioryctria albovittella, from moth-susceptible pinyon pines (Pinus edilis), ectomycorrhizal communities associated with these trees did not differ from the communities on susceptible trees that had received continued herbivory (Sthultz et al. 2009). Thus, the moth did not appear to impose selection on the ectomycorrhizal community of its host plant. However, ectomycorrhizal communities on resistant trees significantly differed from those on susceptible trees, so it is possible that the moth can impose indirect selection on the ectomycorrhizal community by favouring tree genotypes with insect resistance traits. Heath \& Lau (2011) also failed to find evidence that the generalist herbivore, Spodoptera exigua, alters selection between barrel 
medic (Medicago truncatula) and its associated rhizobium, Sinorhizobium meliloti. Herbivory generally increased the nodulation rate, but did not significantly alter the strength or direction of the effect of the rhizobium on the biomass and reproduction across the studied plant families within populations.

\section{Synthesis and future directions}

\author{
TOWARDS MULTIFACETED THREE-WAY \\ EVOLUTIONARY INTERACTIONS BETWEEN PLANTS, \\ MICROBES AND ARTHROPODS
}

In the two decades since Barbosa, Krischik \& Jones (1991) published their seminal book on microbial mediation of plant-insect interactions, numerous studies have contributed to our insight into the fascinating and intricate ways in which microbes, often as 'hidden players', affect interactions between plants and arthropods and the molecular mechanisms underlying these effects (Pieterse et al. 2012). While the huge ecological implications of such three-way interactions have long been recognized, it is only recently that the importance of these three-way interactions for the evolution of the species involved becomes fully appreciated. Microbes exert strong effects on the nutritional, defensive and stress tolerance abilities of their arthropod and plant hosts. These effects in turn can strongly impact the evolutionary trajectories on three-way interactions (Janson et al. 2008), both by modifying the range of species that their hosts can exploit or resist, respectively (ecological opportunity), and by imposing benefits or costs that are contingent upon host genotype (modulating selection in plant-arthropod interactions). We explicitly surveyed genetic variation in the effects of microbes on plant-arthropod interactions, a basic requirement for their ability to affect evolution in three-way interactions by modulating selection. Our survey revealed the ubiquity of such conditional effects across the whole spectrum of microbes, from arthropod- to plant-associated microbes, from mutualists to antagonists and from obligate and facultative endosymbionts to ectosymbionts. Effects of microbes on plant-arthropod interactions were generally contingent upon the genotype of at least one of the species involved (microbe, plant or arthropod), and in a few investigated cases on more than one (e.g. $G_{P} \times G_{A} \times E_{M}$, Table 1), indicating the potential for evolutionary and co-evolutionary responses to microbially mediated selection. We expect that such microbially mediated selection may in fact be common and that it may be a frequently overlooked aspect of evolutionary differentiation and adaptation in plant-arthropod interactions. Our survey further illustrates that microbial mediation of plant-arthropod interactions represents only one facet of a complex set of three-way interactions occurring between plants, microbes and arthropods (Fig. 1, arrows 4-6). Likewise, plants can mediate evolutionary interactions between arthropods and microbes, for instance by driving virulence evolution in an arthropod's associated entomopathogen, and arthropods can mediate evolutionary interactions between plants and microbes, for instance by exerting selection on the plant's rhizosphere microbial community. Ultimately, plant-microbe-arthropod interactions provide an arena for dynamic evolutionary responses and counter-responses among all the partners. This is exemplified by studies of plant virus-vector interactions suggesting that evolved behavioural responses of arthropod vectors to phenotypic variation in particular plant traits have in turn exerted selection on plant viruses to modulate these plant traits in ways that evoke the precise vector behaviour that optimizes their transmission (e.g. Mauck et al. 2012).

\section{LOCAL ADAPTATION IN THREE-WAY INTERACTIONS}

In the Introduction, we have shown that the concept of local adaptation in two-way interactions can be simply extended to three-way interactions by including how the fitness of the directly interacting species is modulated by the local genotypes or local presence/absence of an associated third species. In the simplest case (strictly vertical transmission of a microbial symbiont associated with either the plant or the arthropod), selection may essentially operate at the level of the 'holosymbiont' and the threeway interaction simply reduces to a two-way interaction in terms of local adaptation. In other cases, the three-way interaction will lead to one of a set of more complex patterns of local adaptation, some of which are illustrated in Fig. 2. In our survey of evolutionary studies of three-way interactions between plants, microbes and arthropods, we found only few studies that addressed local adaptation in these more complex interactions. Nonetheless, these few studies clearly show that consumer species can evolutionarily adapt to the local host phenotypes that are induced by a third species. The most clear-cut examples that we have seen are arthropods (spider mites) that evolutionarily adapt to the phenotypes of their host plants that are induced by the host plant's local microbial associates (mycorrhizae) (Bonte et al. 2010) and microbes (viral entomopathogens) that evolutionarily adapt to the phenotypes of their herbivore hosts that are induced by their local food plants (Cory \& Myers 2004). This importantly indicates that local adaptation is not a phenomenon restricted to organisms that directly interact, but can also occur between species that interact only indirectly, emphasizing that indirect interactions can have ecological as well as important evolutionary consequences. Moreover, it stresses the need to conduct local adaptation studies in their proper ecological context. If a consumer species locally adapts to the phenotypes of its host that are induced by an associated third species, studies that do not incorporate this third species will obviously fail to detect this pattern of local adaptation.

Meta-analyses of local adaptation in two-way interactions between parasites and their plant or animal hosts are 
now starting to reveal patterns that provide insight into key factors that determine whether a host or parasite is likely to show local adaptation (e.g. Greischar \& Koskella 2007; Hoeksema \& Forde 2008). At present, there are far too few studies to reveal any patterns of local adaptation in three-way interactions. For example, is local adaptation more frequently occurring among directly than among indirectly interacting species? Does the probability that local adaptation is driven by an indirectly interacting species depend on the mechanism underlying the indirect interaction? Which of the three partners is most likely to show local adaptation and to whom? What is the role of transmission mode, dispersal ability, life history, etc.? One factor expected to facilitate local adaptation to evolve in three-way interactions is a high consistency of the association between the plant, herbivore and microbe across generations within local populations. This is supported by the finding (Cory \& Myers 2004) that adaptation of entomopathogens to the arthropod phenotypes induced by their local food plants occurred in stable host populations, but not in populations where arthropods and entomopathogens frequently went extinct and then recolonized from populations that could have been dominated by other food plants. For the same reason, local adaptation may not be observed in three-way interactions involving species that have only recently been introduced (Raymond et al. 2002).

\section{FUTURE DIRECTIONS}

The importance of three-way interactions in evolutionary diversification and adaptation in plant-arthropod, plant-microbe and arthropod-microbe interactions is now becoming fully appreciated. An important step forward has been the recent insight that modification of host or consumer traits by a third species can alter their evolutionary trajectories and patterns of local adaptation. However, surprisingly, none of the studies have addressed the question of how important these indirect interactions are in driving patterns of local adaptation as compared to the more direct two-way interactions. For example, if arthropods adapt to their local host plant population, how often do they adapt to the specific plant phenotypes induced by their local microbial symbionts rather than to the host plants per se? Unfortunately, studies performed thus far cannot answer this question because, to our knowledge, no published studies to date have explored the performance of any species in a full factorial combination of local versus non-local plants, local versus non-local microbes and local versus non-local herbivores from natural populations. As mentioned earlier, a uniform non-local stock of herbivores was used to test whether entomopathogen virulence was higher on herbivores reared on host plants that were local versus non-local to the entomopathogen (Cory \& Myers 2004). Likewise, evolutionary adaptation of spider mites to the mycorrhizal associate of its host plant was studied using a uniform plant line (Bonte et al. 2010). This is not surprising; experiments testing the full set of local versus non-local plants, microbes and insects would be logistically very demanding. However, without such studies, it is hard to find out whether indirect interactions are generally insignificant for patterns of local adaptation (Fig. 2a), play an equal role (Fig. 2b) or are modifying (Fig. 2c) or even dominating (Fig. 2d) the patterns of local adaptation (Fig. 2d). Such full factorial studies will then provide insight into whether a full understanding of the pattern of local adaptation requires inclusion of local versus non-local combinations of third species that mediate the interaction or not. For many of the potential microbial mediators of indirect interactions, their role in adaptation has been difficult to assess because of a lack of proper methods to determine their presence and screen for genetic variants. The rapid development of novel molecular tools that are now widening our opportunities for identification of this large community of 'hidden' plant and insect symbionts and pathogens, as well as screening for their genetic variants within populations, will enable studies contributing to a better understanding of their role as mediators of adaptation in more complex biotic interactions in the near future.

Overall, our review provides strong evidence that threeway interactions among plants, microbes and arthropods play an important role in shaping evolutionary patterns in natural and agricultural communities. However, our ability to predict where and when we need to incorporate a threeway perspective to understand evolutionary trajectories is still limited. We hope this review will stimulate work that will eventually lead to such an understanding of the evolutionary implications of three-way interactions.

\section{Acknowledgements}

We would like to thank two anonymous reviewers for their constructive comments on an earlier version of the manuscript. Publication 5424 of the Netherlands Institute of Ecology (NIOO-KNAW).

\section{References}

Allison, J.D. \& Hare, J.D. (2009) Learned and naive natural enemy responses and the interpretation of volatile organic compounds as cues or signals. New Phytologist, 184, 768-782.

Barbercheck, M.E., Wang, J. \& Brownie, C. (2003) Adaptation of the entomopathogenic nematode, Steinernema carpocapsae, to insect food plant. Biological Control, 27, 81-94.

Barbosa, P., Krischik, V.A. \& Jones, C.G. (1991) Microbial Mediation of Plant-Herbivore Interactions. John Wiley and Sons, New York, USA.

Begon, M., Harper, J.L. \& Townsend, C.R. (2005) Ecology - From Individual to Ecosystems. John Wiley and Sons, New York, USA.

Biere, A. \& Honders, S.C. (2006) Coping with third parties in a nursery pollination mutualism: Hadena bicruris avoids oviposition on pathogeninfected, less rewarding Silene latifolia. New Phytologist, 169, 719-727.

Biere, A., Elzinga, J.A., Honders, S.C. \& Harvey, J.A. (2002) A plant pathogen reduces the enemy-free space of an insect herbivore on a shared host plant. Proceedings of the Royal Society B-Biological Sciences, 269, 2197-2204.

Bieri, A.P.S., Harri, S.A., Vorburger, C. \& Muller, C.B. (2009) Aphid genotypes vary in their response to the presence of fungal endosymbionts in host plants. Journal of Evolutionary Biology, 22, 1775-1780.

Blanc, S., Uzest, M. \& Drucker, M. (2011) New research horizons in vector-transmission of plant viruses. Current Opinion in Microbiology, 14, $483-491$. 
Bonte, D., De Roissart, A., Vandegehuchte, M.L., Ballhorn, D.J., Van Leeuwen, T. \& de la Peña, E. (2010) Local adaptation of aboveground herbivores towards plant phenotypes induced by soil biota. PLOS ONE, 5, el1174.

Bosque-Pérez, N.A. \& Eigenbrode, S.D. (2011) The influence of virusinduced changes in plants on aphid vectors: insights from luteovirus pathosystems. Virus Research, 159, 201-205.

Bultman, T.L., Aguilera, A. \& Sullivan, T. (2012) Influence of fungal isolates infecting tall fescue on multitrophic interactions. Fungal Ecology, 5, 372-378.

Bultman, T.L., Pulas, C., Grant, L., Bell, G. \& Sullivan, T.J. (2006) Effects of fungal endophyte isolate on performance and preference of bird cherry-oat aphid. Environmental Entomology, 35, 1690-1695.

Bultman, T.L., Rodstrom, J.L., Radabaugh, K.R., VanDop, J.D., Librizzi, J.M., Longwell, L.L., Pulas, C., Grant, L. \& Sullivan, T.J. (2009) Influence of genetic variation in the fungal endophyte of a grass on an herbivore and its parasitoid. Entomologia Experimentalis et Applicata, 130, 173-180.

Cardoza, Y.J. \& Tumlinson, J.H. (2006) Compatible and incompatible Xanthomonas infections differentially affect herbivore-induced volatile emission by pepper plants. Journal of Chemical Ecology, 32, 1755-1768.

Cory, J.S. \& Ericsson, J.D. (2010) Fungal entomopathogens in a tritrophic context. BioControl, 55, 75-88

Cory, J.S. \& Hoover, K. (2006) Plant-mediated effects in insect-pathogen interactions. Trends in Ecology \& Evolution, 21, 278-286.

Cory, J.S. \& Myers, J.H. (2004) Adaptation in an insect host-plant pathogen interaction. Ecology Letters, 7, 632-639.

Cowgill, S.E. \& Bhagwat, V.R. (1996) Comparison of the efficacy of chemical control and Helicoverpa NPV for the management of Helicoverpa armigera (Hubner) on resistant and susceptible chickpea. Crop Protection, 15, 241-246.

Davis, T.S. \& Hofstetter, R.W. (2012) Plant secondary chemistry mediates the performance of a nutritional symbiont associated with a tree-killing herbivore. Ecology, 93, 421-429.

Dicke, M. \& Sabelis, M.W. (1988) How plants obtain predatory mites as bodyguards. Netherlands Journal of Zoology, 38, 148-165.

Douglas, A.E. (1998) Nutritional interactions in insect-microbial symbioses: Aphids and their symbiotic bacteria Buchnera. Annual Review of Entomology, 43, 17-37.

Duetting, P.S., Ding, H.J., Neufeld, J. \& Eigenbrode, S.D. (2003) Plant waxy bloom on peas affects infection of pea aphids by Pandora neoaphidis. Journal of Invertebrate Pathology, 84, 149-158.

Elliot, S.L., Sabelis, M.W., Janssen, A., van der Geest, L.P.S., Beerling, E.A.M. \& Fransen, J. (2000) Can plants use entomopathogens as bodyguards? Ecology Letters, 3, 228-235.

Feldhaar, H. (2011) Bacterial symbionts as mediators of ecologically important traits of insect hosts. Ecological Entomology, 36, 533-543.

Felton, G.W. \& Korth, K.L. (2000) Trade-offs between pathogen and herbivore resistance. Current Opinion in Plant Biology, 3, 309-314.

Ferrari, J., Scarborough, C.L. \& Godfray, H.C.J. (2007) Genetic variation in the effect of a facultative symbiont on host-plant use by pea aphids. Oecologia, 153, 323-329.

Ferrari, J. \& Vavre, F. (2011) Bacterial symbionts in insects or the story of communities affecting communities. Philosophical Transactions of the Royal Society B-Biological Sciences, 366, 1389-1400.

Ferrari, J., Via, S. \& Godfray, H.C.J. (2008) Population differentiation and genetic variation in performance on eight hosts in the pea aphid complex. Evolution, 62, 2508-2524.

Ferrari, J., West, J.A., Via, S. \& Godfray, H.C.J. (2012) Population genetic structure and secondary symbionts in host-associated populations of the pea aphid complex. Evolution, 66, 375-390.

Frago, E., Dicke, M. \& Godfray, H.C.J. (2012) Insect symbionts as hidden players in insect-plant interactions. Trends in Ecology \& Evolution, 27, 705-711.

Gandon, S. (2002) Local adaptation and the geometry of host-parasite coevolution. Ecology Letters, 5, 246-256.

Gholz, H.L., Wedin, D.A., Smitherman, S.M., Harmon, M.E. \& Parton, W.J. (2000) Long-term dynamics of pine and hardwood litter in contrasting environments: toward a global model of decomposition. Global Change Biology, 6, 751-765.

Gould, F., Kennedy, G.G. \& Johnson, M.T. (1991) Effects of natural enemies on the rate of herbivore adaptation to resistant host plants. Entomologia Experimentalis et Applicata, 58, 1-14.

Gould, S.J. \& Vrba, E.S. (1982) Exaptation - a missing term in the science of form. Paleobiology, 8, 4-15.
Greischar, M.A. \& Koskella, B. (2007) A synthesis of experimental work on parasite local adaptation. Ecology Letters, 10, 418-434.

Gutierrez, S., Michalakis, Y., Van Munster, M. \& Blanc, S. (2013) Plant-feeding by insect vectors can affect life cycle, population genetics and evolution of plant viruses. Functional Ecology, 27, 610-622.

Hamilton, E.W., Frank, D.A., Hinchey, P.M. \& Murray, T.R. (2008) Defoliation induces root exudation and triggers positive rhizospheric feedbacks in a temperate grassland. Soil Biology \& Biochemistry, 40, 2865-2873.

Hansen, A.K. \& Moran, N.A. (2011) Aphid genome expression reveals host-symbiont cooperation in the production of amino acids. Proceedings of the National Academy of Sciences of the United States of America, 108, 2849-2854.

Hartley, S.E. \& Gange, A.C. (2009) Impacts of plant symbiotic fungi on insect herbivores: mutualism in a multitrophic context. Annual Review of Entomology, 54, 323-342.

Hatcher, P.E. (1995) 3-Way interactions between plant-pathogenic fungi, herbivorous insects and their host plants. Biological Reviews, 70, 639-694.

Heath, K.D. \& Lau, J.A. (2011) Herbivores alter the fitness benefits of a plant-rhizobium mutualism. Acta Oecologica-International Journal of Ecology, 37, 87-92.

Hodgson, D.J., Vanbergen, A.J., Hartley, S.E., Hails, R.S. \& Cory, J.S. (2002) Differential selection of baculovirus genotypes mediated by different species of host food plant. Ecology Letters, 5, 512-518.

Hoeksema, J.D. (2010) Ongoing coevolution in mycorrhizal interactions. New Phytologist, 187, 286-300.

Hoeksema, J.D. \& Forde, S.E. (2008) A meta-analysis of factors affecting local adaptation between interacting species. American Naturalist, 171, 275-290.

Hosokawa, T., Kikuchi, Y., Shimada, M. \& Fukatsu, T. (2007) Obligate symbiont involved in pest status of host insect. Proceedings of the Royal Society B-Biological Sciences, 274, 1979-1984.

Jallow, M.F.A., Dugassa-Gobena, D. \& Vidal, S. (2008) Influence of an endophytic fungus on host plant selection by a polyphagous moth via volatile spectrum changes. Arthropod-Plant Interactions, 2, 53-62.

Janson, E.M., Stireman, J.O., Singer, M.S. \& Abbot, P. (2008) Phytophagous insect-microbe mutualisms and adaptive evolutionary diversification. Evolution, 62, 997-1012.

Johnson, M.T., Gould, F. \& Kennedy, G.G. (1997) Effect of an entomopathogen on adaptation of Heliothis virescens populations to transgenic host plants. Entomologia Experimentalis Et Applicata, 83, 121-135.

Jones, C.G. (1984) Microorganisms as mediators of plant resource exploitation by insect herbivores. A New Ecology: Novel Approaches to Integrative Systems (eds P.W. Price, W.S. Gaud \& C.N. Slobodchikoff), pp. 53-99. John Wiley and Sons, New York, USA.

Kawecki, T.J. \& Ebert, D. (2004) Conceptual issues in local adaptation. Ecology Letters, 7, 1225-1241.

Kostenko, O., van de Voorde, T.F.J., Mulder, P.P.J., Van der Putten, W.H. \& Bezemer, T.M. (2012) Legacy effects of aboveground-belowground interactions. Ecology Letters, 15, 813-821.

Laine, A.L. \& Tellier, A. (2008) Heterogeneous selection promotes maintenance of polymorphism in host-parasite interactions. Oikos, 117, $1281-1288$.

Lefevre, T. \& Thomas, F. (2008) Behind the scene, something else is pulling the strings: emphasizing parasitic manipulation in vector-borne diseases. Infection Genetics and Evolution, 8, 504-519.

Leonardo, T.E. (2004) Removal of a specialization-associated symbiont does not affect aphid fitness. Ecology Letters, 7, 461-468.

Lozano-Duran, R., Rosas-Diaz, T., Gusmaroli, G., Luna, A.P., Taconnat, L., Deng, X.W. \& Bejarano, E.R. (2011) Geminiviruses subvert ubiquitination by altering CSN-mediated derubylation of SCF E3 ligase complexes and inhibit jasmonate signaling in Arabidopsis thaliana. Plant Cell, 23, 1014-1032.

MacDonald, S.J., Thomas, G.H. \& Douglas, A.E. (2011) Genetic and metabolic determinants of nutritional phenotype in an insect-bacterial symbiosis. Molecular Ecology, 20, 2073-2084.

Madritch, M.D., Donaldson, J.R. \& Lindroth, R.L. (2007) Canopy herbivory can mediate the influence of plant genotype on soil processes through frass deposition. Soil Biology \& Biochemistry, 39, $1192-1201$.

Madritch, M.D. \& Lindroth, R.L. (2011) Soil microbial communities adapt to genetic variation in leaf litter inputs. Oikos, 120, 1696-1704.

Mann, R.S., Ali, J.G., Hermann, S.L., Tiwari, S., Pelz-Stelinski, K.S., Alborn, H.T. \& Stelinski, L.L. (2012) Induced release of a plant-defense 
volatile 'deceptively' attracts insect vectors to plants infected with a bacterial pathogen. PLoS Pathology, 8, e1002610.

Mauck, K.E., De Moraes, C.M. \& Mescher, M.C. (2010) Deceptive chemical signals induced by a plant virus attract insect vectors to inferior hosts. Proceedings of the National Academy of Sciences of the United States of America, 107, 3600-3605.

Mauck, K., Bosque-Pérez, N.A., Eigenbrode, S.D., De Moraes, C.M. \& Mescher, M.C. (2012) Transmission mechanisms shape pathogen effects on host-vector interactions: evidence from plant viruses. Functional Ecology, 26, 1162-1175.

McLean, A.H.C., van Asch, M., Ferrari, J. \& Godfray, H.C.J. (2011) Effects of bacterial secondary symbionts on host plant use in pea aphids. Proceedings of the Royal Society B-Biological Sciences, 278, 760-766.

McMenemy, L.S., Hartley, S.E., MacFarlane, S.A., Karley, A.J., Shepherd, T. \& Johnson, S.N. (2012) Raspberry viruses manipulate the behaviour of their insect vectors. Entomologia Experimentalis Et Applicata, 144, $56-68$.

van der Meijden, E. \& Klinkhamer, P.G.L. (2000) Conflicting interests of plants and the natural enemies of herbivores. Oikos, 89, 202-208.

Moran, N.A. \& Degnan, P.H. (2006) Functional genomics of Buchnera and the ecology of aphid hosts. Molecular Ecology, 15, 1251-1261.

van Munster, M., Janssen, A., Clerivet, A. \& van den Heuvel, J. (2005) Can plants use an entomopathogenic virus as a defense against herbivores? Oecologia, 143, 396-401.

Oliver, K.M., Degnan, P.H., Burke, G.R. \& Moran, N.A. (2010) Facultative symbionts in aphids and the horizontal transfer of ecologically important traits. Annual Review of Entomology, 55, 247-266.

Peccoud, J., Ollivier, A., Plantegenest, M. \& Simon, J.C. (2009) A continuum of genetic divergence from sympatric host races to species in the pea aphid complex. Proceedings of the National Academy of Sciences of the United States of America, 106, 7495-7500.

Pieterse, C.M.J. \& Dicke, M. (2007) Plant interactions with microbes and insects: from molecular mechanisms to ecology. Trends in Plant Science, 12, 564-569.

Pieterse, C.M.J., Van der Does, D., Zamioudis, C., Leon-Reyes, A. \& Van Wees, S.C.M. (2012) Hormonal modulation of plant immunity. Annual Review of Cell and Developmental Biology, 28, 489-521.

Pineda, A., Dicke, M., Pieterse, C.M.J. \& Pozo, M.J. (2013) Beneficial microbes in a changing environment: are they always helping plants to deal with insects ? Functional Ecology, 27, 574-586

Poulin, R. (1995) "Adaptive" changes in the behaviour of parasitized animals: a critical review. International Journal for Parasitology, 25 , 1371-1383.

Raymond, B. \& Hails, R.S. (2007) Variation in plant resource quality and the transmission and fitness of the winter moth, Operophtera brumata nucleopolyhedrovirus. Biological Control, 41, 237-245.

Raymond, B., Vanbergen, A., Pearce, I., Hartley, S.E., Cory, J.S. \& Hails, R.S. (2002) Host plant species can influence the fitness of herbivore pathogens: the winter moth and its nucleopolyhedrovirus. Oecologia, 131, 533-541.

Rodriguez, R.J., White, J.F., Arnold, A.E. \& Redman, R.S. (2009) Fungal endophytes: diversity and functional roles. New Phytologist, 182 , 314-330.

de Roode, J.C., de Castillejo, C.L.F., Faits, T. \& Alizon, S. (2011) Virulence evolution in response to anti-infection resistance: toxic food plants can select for virulent parasites of monarch butterflies. Journal of Evolutionary Biology, 24, 712-722.

Saverschek, N., Herz, H., Wagner, M. \& Roces, F. (2010) Avoiding plants unsuitable for the symbiotic fungus: learning and long-term memory in leaf-cutting ants. Animal Behaviour, 79, 689-698.

Schluter, D. (2009) Evidence for ecological speciation and its alternative. Science, 323, 737-741.

Schweitzer, J.A., Bailey, J.K., Fischer, D.G., Leroy, C.J., Lonsdorf, E.V. Whitham, T.G. \& Hart, S.C. (2008) Plant-soil-microorganism interactions: heritable relationship between plant genotype and associated soil microorganisms. Ecology, 89, 773-781.

Semenova, T.A., Hughes, D.P., Boomsma, J.J. \& Schiott, M. (2011) Evolutionary patterns of proteinase activity in attine ant fungus gardens. BMC Microbiology, 11, 15.

Shigenobu, S., Watanabe, H., Hattori, M., Sakaki, Y. \& Ishikawa, H. (2000) Genome sequence of the endocellular bacterial symbiont of aphids Buchnera sp APS. Nature, 407, 81-86.

Shikano, I., Ericsson, J.D., Cory, J.S. \& Myers, J.H. (2010) Indirect plantmediated effects on insect immunity and disease resistance in a tritrophic system. Basic and Applied Ecology, 11, 15-22.
Simon, J.C., Carre, S., Boutin, M., Prunier-Leterme, N., Sabater-Munoz, B., Latorre, A. \& Bournoville, R. (2003) Host-based divergence in populations of the pea aphid: insights from nuclear markers and the prevalence of facultative symbionts. Proceedings of the Royal Society B-Biological Sciences, 270, 1703-1712

Smith, D.S., Schweitzer, J.A., Turk, P., Bailey, J.K., Hart, S.C., Shuster, S.M. \& Whitham, T.G. (2012) Soil-mediated local adaptation alters seedling survival and performance. Plant and Soil, 352, 243-251.

Sosagomez, D.R., Alves, S.B. \& Marchini, L.C. (1991) Variation in the susceptibility of Bombyx mori $\mathrm{L}$ to nuclear polyhedrosis-virus when reared on different mulberry genotypes. Journal of Applied Entomology-Zeitschrift fur Angewandte Entomologie, 111, 318-320

Stafford, C.A., Walker, G.P. \& Ullman, D.E. (2011) Infection with a plant virus modifies vector feeding behavior. Proceedings of the National Academy of Sciences of the United States of America, 108, 9350-9355.

Sthultz, C.M., Whitham, T.G., Kennedy, K., Deckert, R. \& Gehring, C.A. (2009) Genetically based susceptibility to herbivory influences the ectomycorrhizal fungal communities of a foundation tree species. New Phytologist, 184, 657-667.

Stout, M.J., Thaler, J.S. \& Thomma, B.P.H.J. (2006) Plant-mediated interactions between pathogenic microorganisms and herbivorous arthropods. Annual Review of Entomology, 51, 663-689.

Strauss, S.Y., Sahli, H. \& Conner, J.K. (2005) Toward a more trait-centered approach to diffuse (co)evolution. New Phytologist, 165, 81-89.

Tack, A.J.M. \& Dicke, M. (2013) Plant pathogens structure arthropod communities across multiple spatial and temporal scales. Functional Ecology, 27, 633-645.

Takiya, D.M., Tran, P.L., Dietrich, C.H. \& Moran, N.A. (2006) Co-cladogenesis spanning three phyla: leafhoppers (Insecta: Hemiptera: Cicadellidae) and their dual bacterial symbionts. Molecular Ecology, 15, 4175-4191.

Tétard-Jones, C., Kertesz, M.A. \& Preziosi, R.F. (2012) Identification of plant quantitative trait loci modulating a rhizobacteria-aphid indirect effect. PLoS ONE, 7, e41524.

Tétard-Jones, C., Kertesz, M.A., Gallois, P. \& Preziosi, R.F. (2007) Genotype-by-genotype interactions modified by a third species in a plantinsect system. American Naturalist, 170, 492-499.

Thompson, J.N. (1999) Specific hypotheses on the geographic mosaic of coevolution. American Naturalist, 153, S1-S14.

Thrall, P.H., Hochberg, M.E., Burdon, J.J. \& Bever, J.D. (2007) Coevolution of symbiotic mutualists and parasites in a community context. Trends in Ecology \& Evolution, 22, 120-126.

Tsuchida, T., Koga, R. \& Fukatsu, T. (2004) Host plant specialization governed by facultative symbiont. Science, 303, 1989-1989.

Tsuchida, T., Koga, R., Matsumoto, S. \& Fukatsu, T. (2011) Interspecific symbiont transfection confers a novel ecological trait to the recipient insect. Biology Letters, 7, 245-248.

Turlings, T.C.J., Loughrin, J.H., McCall, P.J., Rose, U.S.R., Lewis, W.J. \& Tumlinson, J.H. (1995) How caterpillar-damaged plants protect themselves by attracting parasitic wasps. Proceedings of the National Academy of Sciences of the United States of America, 92, 4169-4174.

Via, S. (1991) Specialized host plant performance of pea aphid clones is not altered by experience. Ecology, 72, 1420-1427.

Vogel, K.J. \& Moran, N.A. (2011) Sources of variation in dietary requirements in an obligate nutritional symbiosis. Proceedings of the Royal Society B-Biological Sciences, 278, 115-121.

Wernegreen, J.J. \& Moran, N.A. (2000) Decay of mutualistic potential in aphid endosymbionts through silencing of biosynthetic loci: Buchnera of Diuraphis. Proceedings of the Royal Society of London Series B-Biological Sciences, 267, 1423-1431.

White, J.A. (2011) Caught in the act: rapid, symbiont-driven evolution. Endosymbiont infection is a mechanism generating rapid evolution in some arthropods - but how widespread is the phenomenon? BioEssays, 33, 823-829.

Wilson, A.C.C., Ashton, P.D., Calevro, F., Charles, H., Colella, S., Febvay, G., Jander, G., Kushlan, P.F., Macdonald, S.J., Schwartz, J.F., Thomas, G.H. \& Douglas, A.E. (2010) Genomic insight into the amino acid relations of the pea aphid, Acyrthosiphon pisum, with its symbiotic bacterium Buchnera aphidicola. Insect Molecular Biology, 19, 249-258.

Wolinska, J. \& King, K.C. (2009) Environment can alter selection in hostparasite interactions. Trends in Parasitology, 25, 236-244.

Received 27 November 2012; accepted 1 March 2013

Handling Editor: Alison Bennett 